\title{
Determining the Effect of Green Spaces on Urban Heat Distribution Using Satellite Imagery
}

\author{
Hyun-Ah Choi, Woo-Kyun Lee* and Woo-Hyuk Byun \\ Department of Environmental Science and Ecological Engineering, Graduate School, Korea University, Seoul 136-701, Korea
}

*Corresponding author. Tel: +82-2-3290-3016, E-mail: leewk@korea.ac.kr

\begin{abstract}
Urbanization has led to a reduction in green spaces and thus transformed the spatial pattern of urban land use. An increase in air temperature directly affects forest vegetation, phenology, and biodiversity in urban areas. In this paper, we analyze the changing land use patterns and urban heat distribution (UHD) in Seoul on the basis of a spatial assessment. It is necessary to monitor and assess the functions of green spaces in order to understand the changes in the green space. In addition, we estimated the influence of green space on urban temperature using Landsat 7 Enhanced Thematic Mapper Plus (ETM+) imagery and climatic data. Results of the assessment showed that UHD differences cause differences in temperature variation and the spatial extent of temperature reducing effects due to urban green space. The ratio of urban heat area to green space cooling area increases rapidly with increasing distance from a green space boundary. This shows that urban green space plays an important role for mitigating urban heating in central areas. This study demonstrated the importance of green space by characterizing the spatiotemporal variations in temperature associated with urban green spaces.
\end{abstract}

Key words: Urban green space, Spatio-temporal, Urban Heat Distribution (UHD), Satellite imagery

\section{INTRODUCTION}

Cities worldwide have begun to experience the impacts of climate change. As temperatures and precipitation patterns change, urban areas are expected encounter a wide range of challenges (IPCC, 2007). Extreme and/or prolonged high temperatures are being considered as a serious climate hazard, as demonstrated by the severe consequences of recent heat wave events (Gosling et al., 2009). Urban areas, in particular, are more vulnerable to these effects because of the presence of urban heat islands. Furthermore, the projected temperature rise, together with the tendency toward urbanization, suggests that the urban thermal environment may probably become increasingly uncomfortable in the future. This will have a direct impact on the urban population and infrastructure (Smith et al., 2009). In urban areas anthropogenic heat is produced from heating and cooling processes in buildings and vehicles. This inadvertent climate modification is called the Urban Heat Island (UHI) effect (Arnfield, 2003; Gomez et al., 1998; Landsberg, 1981; Howard, 1833). However, urban green space, such as forests or parks, can the ameliorate UHI effect by preventing incoming solar radiation from heating the surrounding buildings and surfaces, cooling the air by evapotranspiration, and reducing wind speed (Akbari et al., 2001). The cooling effect of green spaces during the hot and humid summer season is especially important, and they are regarded as natural resources for city planning (Narita et al., 2002). Moreover, urban parks with forests can reduce surface water runoff (by intercepting precipitation), absorb pollutants, and emit hydrocarbons as well as modify solar radiation, air temperature, wind speed, and relative humidity. Thus, increased vegetative cover and higher-albedo surface materials are strategies can help realize cooling effects in urban areas (Jonsson, 2004; Jauregui, 1997). Moreover, urban parks are now an important urban infrastructure for mitigating UHIs in the era of global warming (Lee et al., 2009).

The UHI effect has been reported in many cities such as Buenos Aires, Argentina; New York City, USA; Lisbon, Portugal; Prague, Czech Republic; and Debrecen, Hungary (Choi et al., 2008). In Korea, researches on UHI for Seoul, Incheon, Daejeon, Daegu, Gwangju and Busan, have also been recently reported (Choi et al., 2008; Kim and Baik, 2005, 2004; Chung et al., 2004). Furthermore, many studies have been carried out in other countries on the cooling effect of urban parks or green spaces (Chang et al., 2007; Correa et al., 2006; Wong and Chen, 2004; Svensson and Eliasson, 2002; Eliasson and Upmanis, 2000; Upmanis et 
al., 1998). In Korea, Kwon and Lee (2001) studied the cooling effects of Changdeok Palace in Seoul. Yoon and co-worker studied the cooling effects of urban parks in Seoul (Yoon, 2003; Yoon and Bae, 2002), but the study periods were less than two months. In fact, few studies have examined the cooling effects created by urban parks in Korea and the relationship between urban climate and open space planning has not been examined (Lee et al., 2009). This study attempts to close this gap by analyzing whether and how green spaces reduce the temperature in UHIs by performing spatial and seasonal variation analysis.

\section{DATA AND METHODS}

\subsection{Study Site Description and Characteristics of Land Use}

The study area covered in this paper is Seoul, $126^{\circ}$ $62^{\prime} \mathrm{E}-127^{\circ} 48^{\prime} \mathrm{E}$ and $37^{\circ} 25^{\prime} \mathrm{N}-37^{\circ} 99^{\prime} \mathrm{N}$. Seoul is located in the Han River Basin, where the Han River flows through the central part of the Korean Peninsula. The annual variation in its mean annual temperature and total annual precipitation is largely due to topographical effects. Its yearly precipitation reaches $1,488 \mathrm{~mm}$, and the average temperature is $12.5^{\circ} \mathrm{C}$ (the average for the last 10 years; 1991-2000) (Song et al., 2005; Seoul Metropolitan Government, 2001). Since the 1960s, Seoul has experienced rapid urbanization, in particular because of migration of people from rural areas to the city, thus resulting in population concentration. The current population of the city itself is about ten million, and that of the Seoul Metropolitan Area is more than twenty million (Lee et al., 2009). Table 1 shows the land use in Seoul in 2001 (Seoul Metropolitan Government, 2001) and the main land use types where their fractional areas differ for each Gu-an administrative subregion. In general, residential and commercial areas are mixed throughout the city, except for $\mathrm{Gu}$ that have large green areas. Commercial sectors are densely aggregated in Jung-gu, the southern part of Jongro-gu, and in Gangnam-gu, where station 1 is located (KMA, 2001; Fig. 1).

\section{2 Methods}

It is necessary to estimate surface temperature in order to assess the climate change impact of urban forest. It is also important to observe, inter alia, thermal and forest distributions. All of this can be done via satellite remote sensing systems, which can provide us with countermeasures for environmental issues and prediction methodologies for natural disasters (Suga et al., 2003). With this in mind, we used 30-m spatial resolution Landsat 7 Enhanced Thematic Mapper Plus
Table 1. Land use in Seoul(SMG, 2001).

\begin{tabular}{|c|c|c|c|}
\hline & & Area (ha) & Rate \\
\hline \multirow{5}{*}{ Developed area } & Residential & 16350.6 & $27.1 \%$ \\
\hline & Commercial & 6152.7 & $10.2 \%$ \\
\hline & Industrial & 814.1 & $1.3 \%$ \\
\hline & Road & 6169.1 & $10.2 \%$ \\
\hline & Others & 6307.6 & $10.4 \%$ \\
\hline \multirow{4}{*}{ Green space area } & Agricultural & 3000.5 & $5.0 \%$ \\
\hline & Burial & 213.8 & $0.4 \%$ \\
\hline & Forest & 15994.9 & $26.5 \%$ \\
\hline & Others & 1418.7 & $2.3 \%$ \\
\hline \multirow[t]{2}{*}{ Water } & Han River and stream & 3987.2 & $6.6 \%$ \\
\hline & & 60409.2 & $100.0 \%$ \\
\hline
\end{tabular}

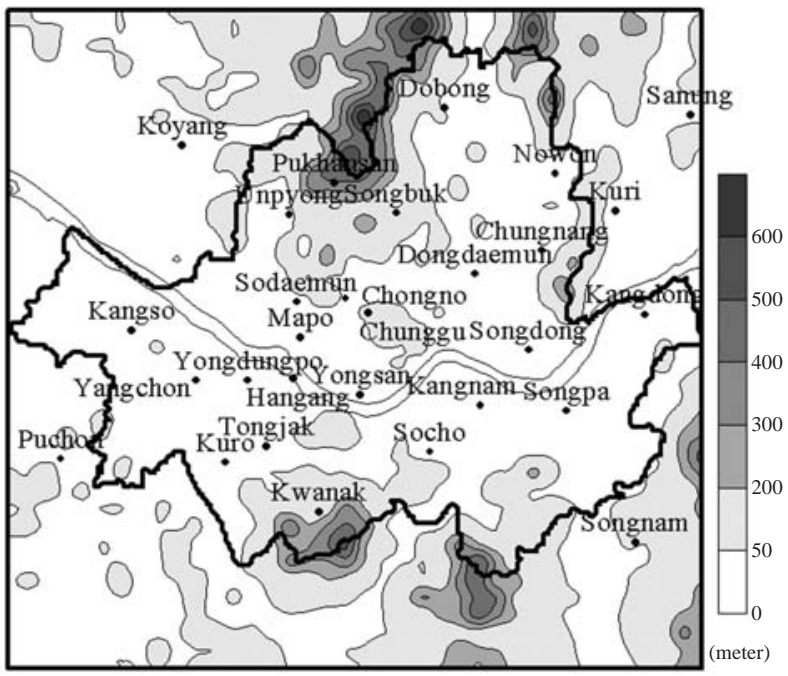

Fig. 1. Automatic weather stations in Seoul (KMA, 2000).

$(\mathrm{ETM}+)$ images in order to extract patterns and detect changes in the spatio-temporal makeup of urban surfaces. All those images covering the scene numbered 116/34 in the Landsat WRS-2 system for the year 2002 were used. The Landsat 7 ETM+ images were interpreted with ERDAS image 9.1 analysis programs.

\section{3 Data Analysis}

\section{3. 1 Satellite Imagery Analysis for Urban Heat Distribution (UHD)}

In this study, the surface temperature is calibrated from the DN (Digital Number) of Landsat ETM+ imagery, which represents the absolute radiation of land cover; the calibration is based on the NASA model. For each DN from ETM+ imagery, we subtract the spectral radiance $\mathrm{L}_{\lambda}$ using the official NASA approved ranges $\operatorname{LMIN}_{\lambda}$ and $\operatorname{LMAX}_{\lambda}$ as shown in the following 
equation (Eq. 1; Melesse, 2004; Chander and Markham, 2003).

$$
\mathrm{L}_{\lambda}=\left\{\left(\mathrm{L}_{\max }-\mathrm{L}_{\min }\right) / \mathrm{DN}_{\max }\right\} * \mathrm{DN}+\mathrm{L}_{\text {min }}
$$

where,

$\mathrm{L}_{\max }=$ the spectral radiance $\mathrm{t}$ scaled to $\mathrm{DN}_{\max }$;

$\mathrm{L}_{\min }=$ the spectral radiance scaled to $\mathrm{DN}_{\min }$;

$\mathrm{DN}=$ the quantized calibrated pixel value;

$\mathrm{DN}_{\max }=$ the Maximum DN.

Following Eq. 1, which states the relationship between the spectral radiance value $\mathrm{L}_{\lambda}$ and the absolute temperature in Kelvin, we can estimate the absolute temperature of the land surface $(\mathrm{T})$. This is expressed in Eq. 2 (Melesse, 2004; Mobasheri and Mousavi, 2004).

$$
\mathrm{T}=\frac{\mathrm{K}_{2}}{\ln \left[\left(\mathrm{K}_{1} / \mathrm{L}_{\lambda}\right)+1\right]}
$$

where,

$\mathrm{T}$ is the effective at-satellite temperature in Kelvin; $\mathrm{K}_{1}(666.09)$ is the post-calibration constant of spectral radiance in $\mathrm{W} /\left(\mathrm{m}^{2} \mathrm{sr} \mu \mathrm{m}\right)$;

$\mathrm{K}_{2}$ (1282.71) is the post-calibration constant of absolute temperature in temperature degrees (Kelvin);

$\mathrm{L}_{\lambda}$ is the spectral radiance in $\mathrm{W} /\left(\mathrm{m}^{2} \mathrm{sr} \mu \mathrm{m}\right)$.

\subsubsection{Spatial Autocorrelation Analysis of UHD}

We performed variogram analysis and kriging interpolation (Lee et al., 2006; Webster and Oliver, 2001; Mowrer and Congalton, 2000; Bailey and Gatrell, 1995) in order to identify the spatial autocorrelation and variability; modern objected-oriented language and the SPLUS system, with the optional S+SpatialStats module (Bao et al., 2000; MathSoft, 1997), were employed. In this study, the variogram is used to measure the spatial variation in imagery by automatically fitting spherical variogram parameters (nugget, sill, and range). The sill is an indicator of the spatial variability of the data, and the range is the distance at which the variogram reaches the sill. A discontinuity of the variogram at the origin, also called the nugget effect, can be related to either uncorrelated noise (measurement error) or to spatial structures at a length scale smaller than the pixel size. The characteristic shape and range of the spherical variogram are of primary importance for ordinary kriging because of the invariance of weights under linear transformation of the variogram (Genton, 1995).

Kriging is based on the assumption that the parameter being interpolated can be treated as a regionalized variable. The weights of kriging are derived from the kriging equations using a semivariance function. The parameters of the semivariance function and the nugget effect can be estimated by an empirical semivariance function (Webster and Oliver, 2007). An unbiased estimator of the semivariance function is half the average squared difference between paired data values:

$$
\gamma(\mathrm{h})=\frac{1}{2 \mathrm{~N}(\mathrm{~h})} \sum_{\mathrm{i}=1}^{\mathrm{N}(\mathrm{h})}\left[\mathrm{z}\left(\mathrm{x}_{\mathrm{i}}\right)-\mathrm{z}\left(\mathrm{x}_{\mathrm{i}}+\mathrm{h}\right)\right]^{2}
$$

where,

$\gamma(\mathrm{h})$ is the semivariance value at distance interval $\mathrm{h}$;

$\mathrm{N}(\mathrm{h})$ is the number of sample pairs within the distance interval $\mathrm{h}$;

$\mathrm{z}\left(\mathrm{x}_{\mathrm{i}}+\mathrm{h}\right)$ and $\mathrm{z}\left(\mathrm{x}_{\mathrm{i}}\right)$ are sample values at two points separated by the distance interval $h$.

This method uses a variogram to express the spatial variation and minimizes the errors in the estimated values, which are calculated on the basis of the spatial distribution of the estimated values (Fortin and Dale, 2005; Journel and Huijbregts, 1981; Matheron, 1963).

\subsubsection{Analyzing the Effect of Green Space on UHD}

From the variogram analysis, a map for UHD was prepared using the inverse distance squared weighting (IDSW) analysis. Urban heat island effects may constitute a major portion of the remaining error, especially in the case of daily minimum temperature (Choi et al., 2003). The urban effect has been shown to increase as a logarithmic function of population difference (Oke, 1981). Hence, the same method as for elevation correction may be applied to the urban effect correction, if a suitable proxy variable that accurately represents the urban effect (e.g., population) is available. Using the power of 2 for the inverse weighting factor, an interpolation model for temperature estimation can be written as (Choi et al., 2003):

$\mathrm{T}=\frac{\sum \frac{\mathrm{T}_{\mathrm{i}}}{\mathrm{d}_{\mathrm{i}}^{2}}}{\sum \frac{1}{\mathrm{~d}_{\mathrm{i}}^{2}}}+\left[\mathrm{z}-\frac{\sum \frac{\mathrm{z}_{\mathrm{i}}}{\mathrm{d}_{\mathrm{i}}^{2}}}{\sum \frac{1}{\mathrm{~d}_{\mathrm{i}}^{2}}}\right] \Gamma+\log \left[\mathrm{p}-\frac{\sum \frac{\mathrm{P}_{\mathrm{i}}}{\mathrm{d}_{\mathrm{i}}^{2}}}{\sum \frac{1}{\mathrm{~d}_{\mathrm{i}}^{2}}}\right] \Pi$

where,

$\mathrm{T}_{\mathrm{i}}$ is the observed temperature at station $\mathrm{i}$;

$\mathrm{d}_{\mathrm{i}}$ is the distance from the site to station $\mathrm{i}$;

$\mathrm{z}$ is the elevation of the site;

$z_{i}$ is the elevation of station $i$;

$\Gamma$ is the temperature change per unit change in the elevation;

$\mathrm{P}$ is a proxy variable for representing the urban effect (population) of the site;

$P_{i}$ is the $P$ value of the city where station $i$ is located;

$\Pi$ is an empirical coefficient for conversion of $\mathrm{P}$ to warming by the urban effect. 
The UHD is graded into the following 5 classes using the natural breaks methods of ArcGIS 9.2: (1) high cooling effect, (2) cooling effect, (3) buffer zone, (4) UH effect, and (5) high UH effect. In addition, the study area was zoned by distance from a green space boundary using buffering analysis. Through the relationship between the distance from a green space boundary and temperature, the effect of green space on UHD was analyzed.
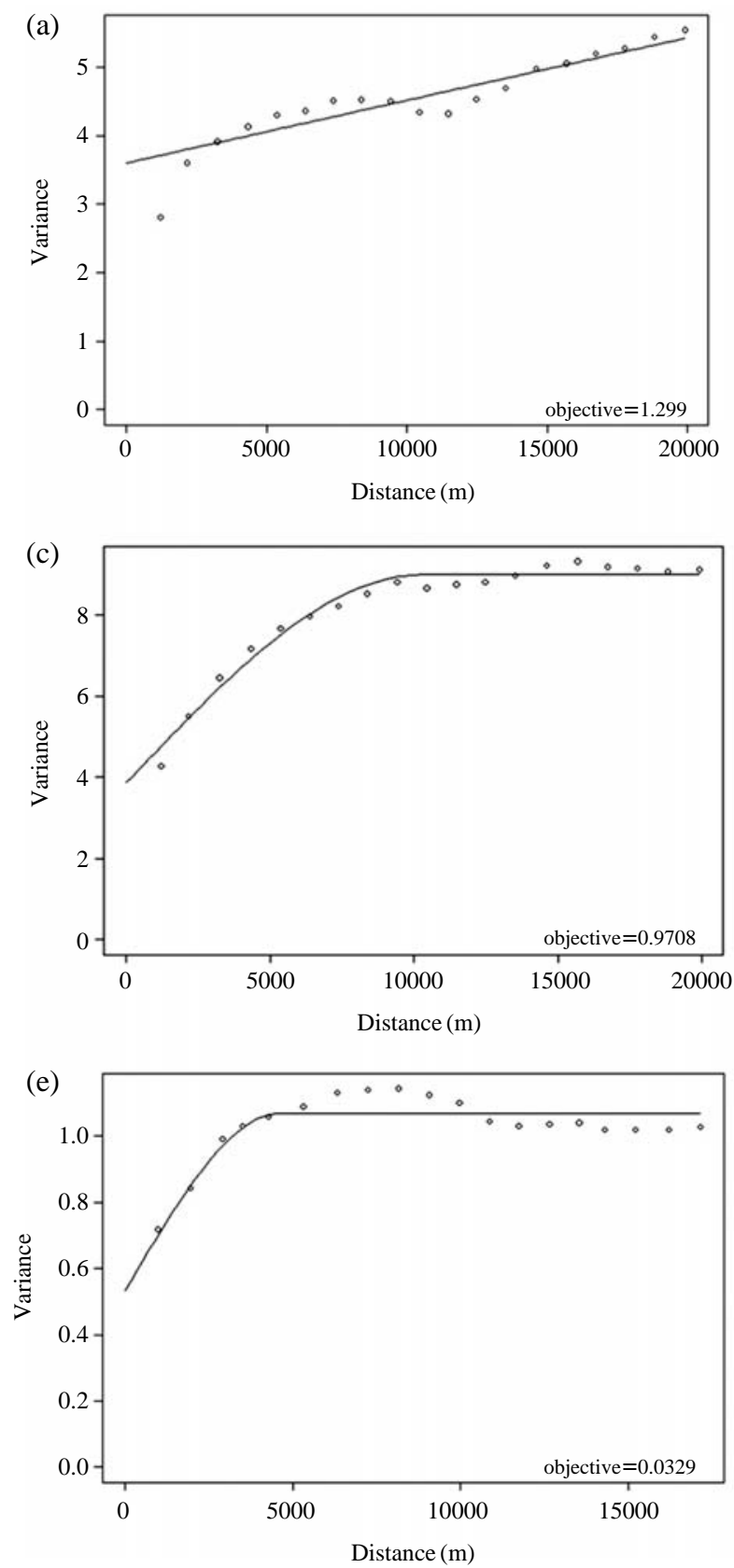

\section{RESULTS AND DISCUSSION}

\section{1 Seasonal UHD}

The surface temperature, which was extracted from AWS data, shows a characteristic behavior. The seasonal variation distributions of urban surface temperature differed greatly depending on the land use and land cover patterns of the surrounding areas. This is in line with the spatial and temporal variability pattern of
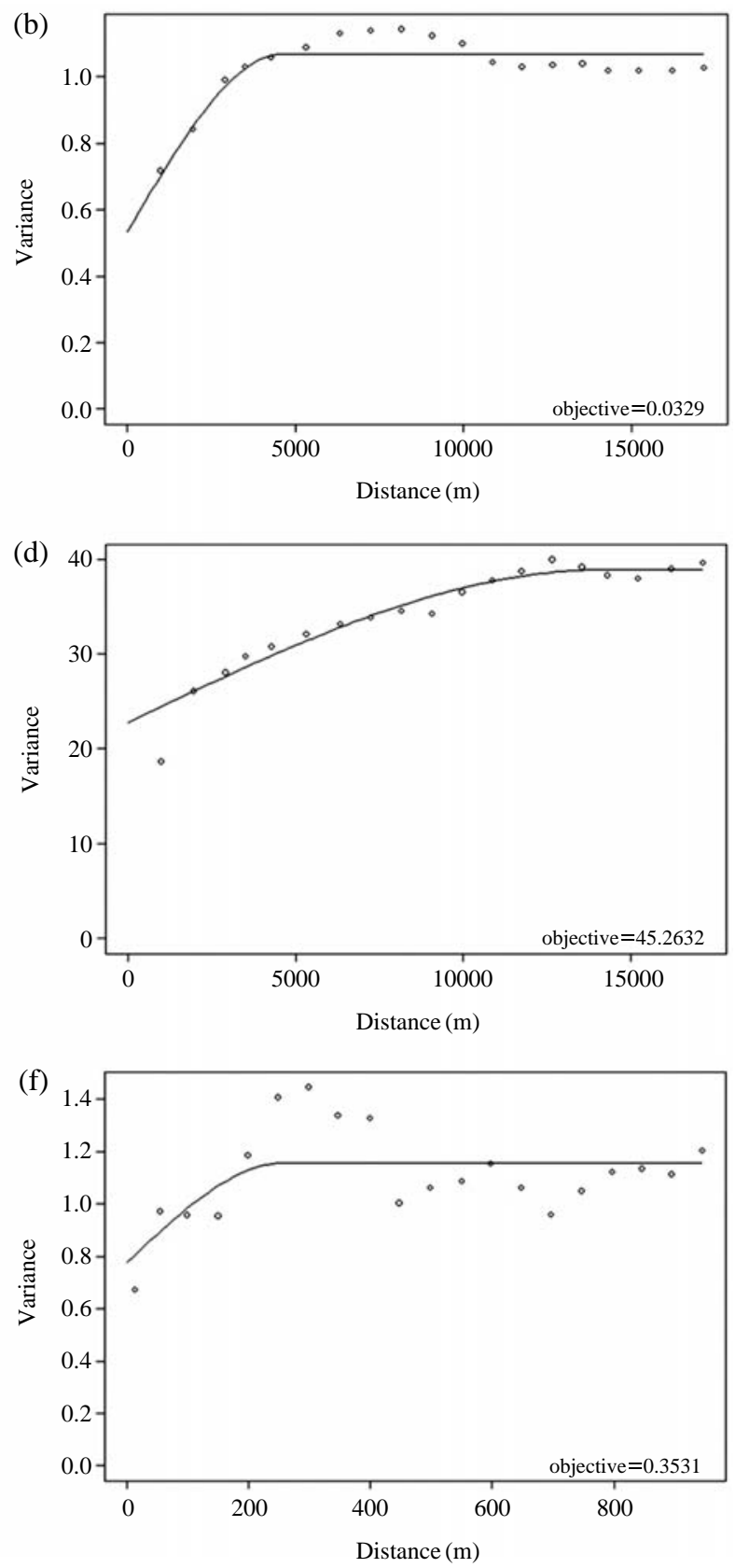

Fig. 2. Spherical variograms of estimated surface temperature at 2-month intervals: (a) February, (b) April, (c) June, (d) August, (e) October, (f) December. 
Table 2. Variogram parameters fitted by the spherical variograms shown in Fig. 2.

\begin{tabular}{lcrrrrr}
\hline & \multicolumn{5}{c}{ Spherical model } \\
\cline { 2 - 6 } & February & \multicolumn{1}{c}{ April } & \multicolumn{1}{c}{ June } & August & October & December \\
\hline Range $(\mathrm{m})$ & 3.93 & 4640.75 & 8818.25 & 14215.63 & 450.83 & 285.83 \\
Sill & 2.60 & 0.53 & 5.26 & 16.21 & 0.38 & 0.38 \\
Nugget & 3.13 & 0.53 & 3.75 & 22.75 & 0.78 & 0.78 \\
\hline
\end{tabular}

Table 3. Variogram parameters fitted by the spherical variogram for forest and urban areas.

\begin{tabular}{|c|c|c|c|c|c|c|}
\hline & \multicolumn{3}{|c|}{ Forest area } & \multicolumn{3}{|c|}{ Urban area } \\
\hline & April & June & August & April & June & August \\
\hline Range (m) & 4157.27 & 4879.73 & 7292.46 & 3566.74 & 3197.5 & 18574.92 \\
\hline Sill & 0.56 & 4.36 & 35.78 & 0.72 & 3.98 & 16.73 \\
\hline Nugget & 0.18 & 3.26 & 9.54 & 0.49 & 4.00 & 23.11 \\
\hline
\end{tabular}

climatic factors in Seoul (Choi et al., 2008). The temperature variability in highly elevated areas was relatively greater than that in less elevated residential areas, but the temperature variability in the former tended to decrease, while the temperature variability in the latter showed an increasing tendency (Choi et al., 2008).

\section{2 Spatial Autocorrelation of UHD}

In order to identify which urban areas have a statistically significant influence on urban temperature and the effects of temperature decrease within urban green areas, we performed analyses at 2-month intervals. The automatic fitting of variogram models to a spherical variogram is represented in Fig. 2 and Table 2. The results indicated that spatial autocorrelation existed within a range of about $4.6 \mathrm{~km}$ to $14.2 \mathrm{~km}$ from the green space boundary in the hot season.

Moreover, spatial autocorrelation in urban green space ranges is stronger than that in urban ranges, especially from $4 \mathrm{~km}$ standards. The variation of the UHD in green space, as characterized by the spatial pattern, showed strong spatial continuity as indicated by the high proportion of each sill showing spatial structure. The range for green space was $4.2 \mathrm{~km}$ to $7.3 \mathrm{~km}$, whereas that for urban areas was $3.6 \mathrm{~km}$ to $18.6 \mathrm{~km}$ from the green space boundary (Table 3 ). However, no specific spatial differences were observed in the summer season. This suggests that spatial variation is decreasing and that the summer is getting warmer in Seoul.

\section{3 Effect of Green Space on UHD}

In order to determine the spatial extent of the cooling effect of green space, we employed the IDSW approach, which considers the temperature lapse rate by elevation as in Fig. 3. It shows that a lower temperature zone existed around high-elevation forests and water areas. A higher temperature zone was found in built up

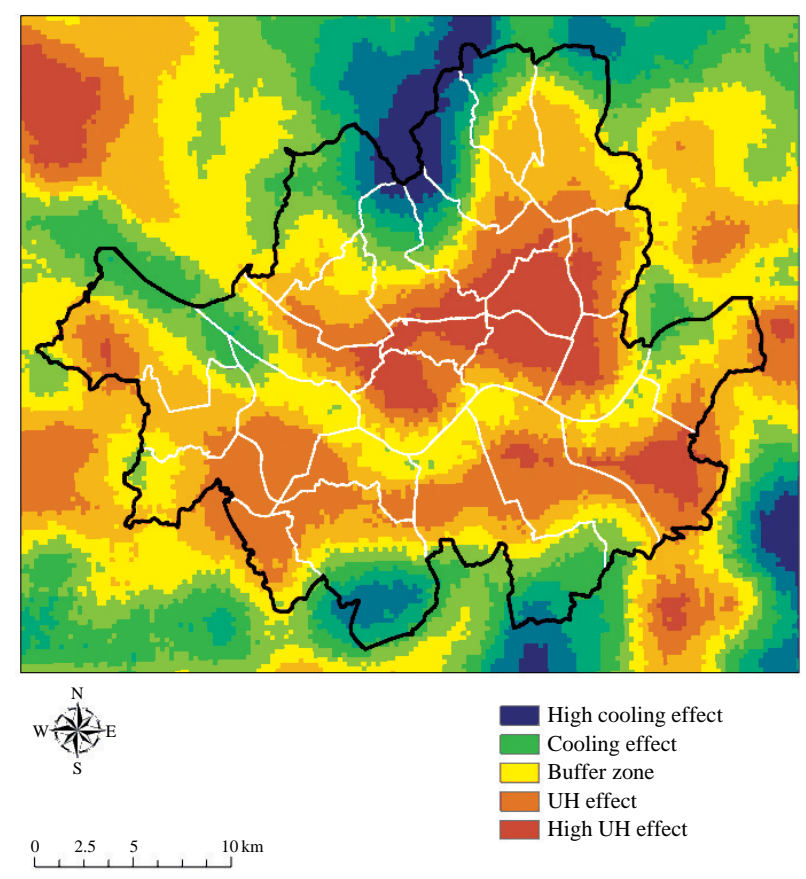

Fig. 3. Effect of green space on UHD.

areas. Especially, UHD effects were clustered towards the center of the built-up area: Jung-gu and Gangnam -gu.

The kappa coefficient to measure total map accuracy was 0.51 , and the overall accuracy of classification was 51.4\% (Table 4). Landis and Koch (1977) categorized perfect agreement as equating to a kappa of 1, while chance agreement would equate to 0 . For this scale, a kappa of 0.51 is in the "moderate" agreement range.

Fig. 4 shows the effect of distance from a green space boundary on UHD temperature reduction. The UHD in Seoul shows that relatively warm regions 
Table 4. Error matrices by number of classification categories and Kappa.

\begin{tabular}{|c|c|c|c|c|c|c|c|}
\hline \multirow[b]{2}{*}{ Classified data } & \multicolumn{6}{|c|}{ Reference (km) } & \multirow{2}{*}{$\begin{array}{c}\text { User's } \\
\text { accuracy } \\
(\%)\end{array}$} \\
\hline & $\begin{array}{l}\text { High cooling } \\
\text { effect }\end{array}$ & $\begin{array}{l}\text { Cooling } \\
\text { effect }\end{array}$ & $\begin{array}{l}\text { Buffer } \\
\text { zone }\end{array}$ & $\begin{array}{c}\text { UHI } \\
\text { effect }\end{array}$ & $\begin{array}{l}\text { High UHI } \\
\text { effect }\end{array}$ & Sum & \\
\hline High cooling effect & 2937 & 1055 & 1 & 0 & 0 & 3993 & 74 \\
\hline Cooling effect & 1464 & 1113 & 2 & 75 & 0 & 2654 & 42 \\
\hline Buffer zone & 1389 & 165 & 248 & 450 & 91 & 2343 & 11 \\
\hline UHI effect & 0 & 7 & 18 & 475 & 129 & 629 & 76 \\
\hline High UHI effect & 0 & 0 & 2 & 41 & 399 & 442 & 90 \\
\hline Sum & 5790 & 2340 & 271 & 1041 & 619 & 10061 & \\
\hline Producer's accuracy (\%) & 51 & 48 & 92 & 46 & 64 & & \\
\hline
\end{tabular}

Overall classification accuracy $=51.4 \%$, Kappa value $=0.51$

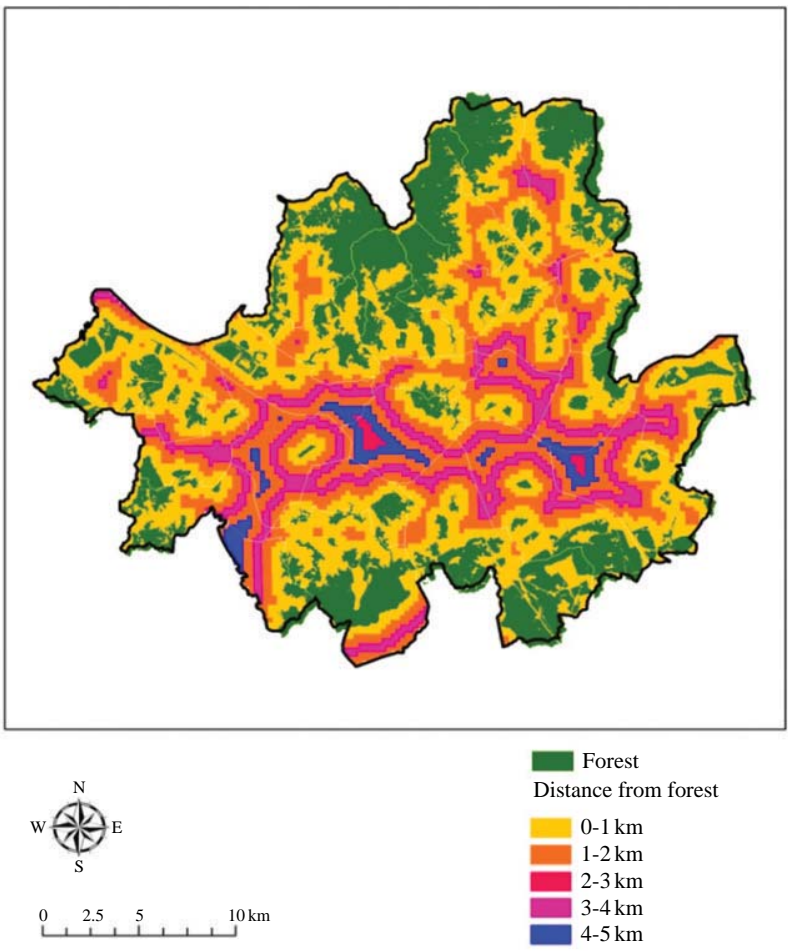

Fig. 4. Distances from the green space boundary.

extend in the east-west direction, while relatively cold regions are located near Mounts Bukhan and Gwanak. Near the border of Seoul, the temperature is, as would be expected, relatively low, except near the southwestern and southeastern borders, where the sprawling expanse of urbanization is already in progress. These results come from the transformation of downtown Seoul; we observe that the center of the Han River, the Gangbuk area, became a focal point for downtown development in the late 1960s according to the Land District Adjustment Plan (Song et al., 2005). Gangnam shows great differences in its history of land use, land development pattern, and space management in com- parison to other areas, and specifically, in comparison to Gangbuk. In addition, the reduction of air temperature by green space can extend to around $4 \mathrm{~km}$. The urban heat island effect decreases with proximity to green space (Fig. 5). This shows that a strong relationship exists between urban thermal excess and distance from the green space boundary, as well as built up ratio.

For urban heat island analysis, an urban station and a rural/suburban station are selected. In the case that there is an urban station and many rural/suburban stations surrounding a city, a better definition of the urban heat island might be the difference between the nearsurface air temperature at the urban station and that averaged for representative rural/suburban stations (Kim and Baik, 2005). Hence, we have selected Gangnam, Yongsan, as a representative urban station and Dongjak, Dobong, for the mitigation area, because this location exhibits the warmest averaged temperature within Seoul and the nearby region has typical urban characteristics and urban forest area. Dongjak, Dobong, showed a lower temperature than the center of the urban area, and was important for mitigation in the UHI reduction area, and Gangnam, Yongsan, showed a higher temperature than other areas. This result is related to the effect of proximity to a green space boundary on UHI temperature reduction. The temperature differences found between forest boundary areas and the core area are significant. A spatial autocorrelation between urban forests within residential areas and the heat island effect is shown.

It is well known that land use type is an important determinant in near-surface air temperature, and a change in land use in an urban location directly influences the temperature therein (Bottyan and Unger, 2003; Deosthali, 2000; Klysik and Fortuniak, 1999; Jauregui et al., 1992; Park, 1986). In addition, the results obtained in this study vary significantly compared with results obtained in Sweden, where a 1,100 m spatial extent of air temperature-reducing effects was 


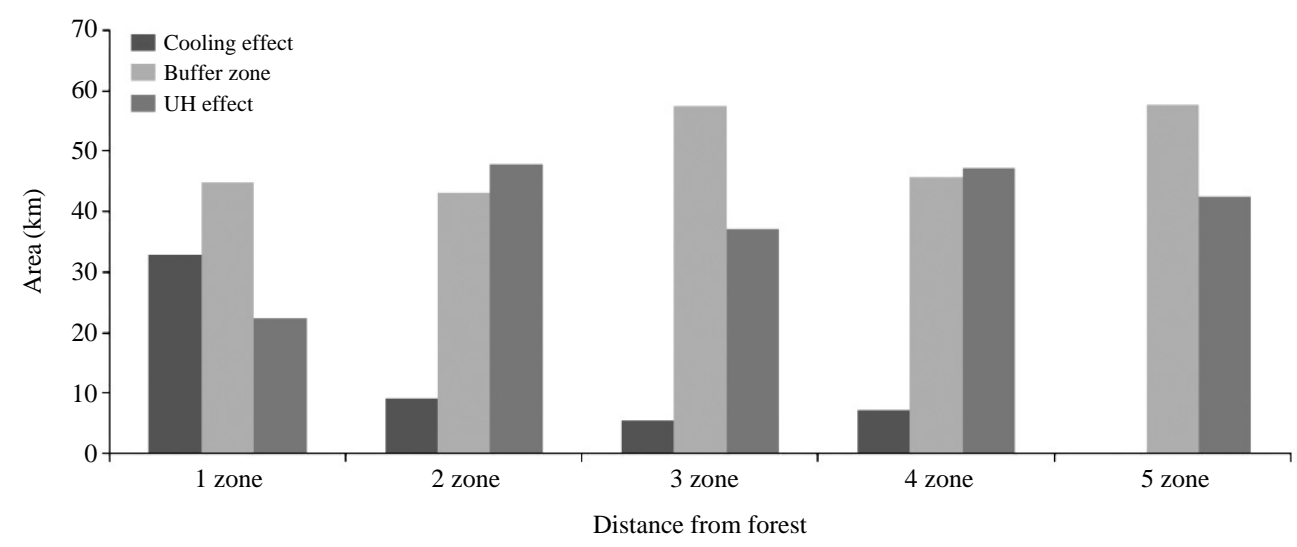

Fig. 5. Effect of distance from green space boundary on urban temperature.

recorded in Göteborg (Upmanis et al., 1998). This is mainly due to the difference between the two study areas in terms of urban structure, cover, fabric, and metabolism. In terms of structure, Seoul is surrounded by dense high rise commercial buildings, especially in the inner area. However, the Göteborg site is within a low-density single family residential area with a high portion of grassed areas and open lots (Lee et al., 2009), where cool air from the urban park freely travels to the surrounding urban areas. The land use is not as dense and the building height to street width ratio $(\mathrm{H} /$ W) is not as high as in Seoul (Lee et al., 2009).

\section{CONCLUSIONS}

This study examined the effect of green space on urban heat distribution in Seoul, using satellite imagery data and near-surface air temperature data measured at 31 AWSs - the spatial and temporal structure of the urban heat island in Seoul. It was found that the UHD deviates considerably from a concentric heat island pattern, and warm areas were attributed to the presence of densely built-up commercial and industrial neighboring sectors. In addition, spatial autocorrelation existed within a range of about $5 \mathrm{~km}$ to $10 \mathrm{~km}$ in the hot season. Moreover, spatial autocorrelation in the vicinity of urban green spaces is shown to be stronger than in the core urban area. However, it does not show any spatial differences in the summer period. We also found that the temperature of green space is quite different from that of the urban area. The effects of temperature decrease due to urban green areas can extend to around $4 \mathrm{~km}$. The ratio of urban heat area to urban cooling area increases with distance from a green space boundary. The analyses showed that urban green space plays an important role for mitigating urban heating in the central urban area. Consequently, we suggest that ensuring a maximum distance of $4 \mathrm{~km}$ from a green space would reduce temperatures in urban areas. This type of research is expected to provide additional observational evidence for theoretical modeling studies (Baik et al., 2001), suggesting that urban green space plays an important role for the mitigation and temperature reduction of UHIs in central areas.

\section{ACKNOWLEDGEMENT}

This study was carried out with the support of 'Forest Science \& Technology Projects (Project No. S101 07L0201004)' provided by Korea Forest Service.

\section{REFERENCES}

Akbari, H., Pomerantz, M., Taha, H. (2001) Cool surface and shades on residential heating and cooling energy use in four Canadian cities. Energy 17(2), 141-149.

Arnfield, A.J. (2003) Two decades of urban climate research: A review of turbulence, exchanges of energy and water, and the urban heat island. International Journal of Climatology 23, 1-26.

Baik, J.J., Kim, Y.H., Chun, H.Y. (2001) Dry and moist convection forced by an urban heat island. Journal of Applied Meteorology 40, 1462-1475.

Bailey, T.C. and Gatrell, A.C. (1995) Interactive spatial data analysis. Longman, Essex, England, pp. 413.

Bao, S., Anselin, L., Martin, D., Stralberg, D. (2000) Seamless integration of spatial statistics and GIS: The SPlus for ArcView and the S+ Grassland Links. Journal of Geographical Systems 2, 287-306.

Bottyan, Z., Unger, J. (2003) A multiple linear statistical model for estimating the mean maximum urban heat island. Theoretical and Applied Climatology 75, 233243.

Chander, G., Markham, B.L. (2003) Revised Landsat-5 
TM Radiometric Calibration Procedures and Post calibration Dynamic Ranges. IEEE Transactions on Geoscience and Remote Sensing 41(11), 2674-2677.

Chang, C., Li, M., Chang, S. (2007) A preliminary study on the local cool-island intensity of Taipei city parks. Landscape and Urban Planning 80(4), 386-395.

Choi, H.A., Lee, W.K., Kim, S.R., Kwak, H.B. (2008) Spatio-temporal variability of temperature and precipitation in Seoul. Journal of the Korea GIS 16(4), 467478.

Choi, J., Chung, U., Yun, J.I. (2003) Urban-effect correction to improve accuracy of spatially interpolated temperature estimates in Korea. Journal of Applied Meteorology 42, 1711-1719.

Chung, U., Choi, J., Yun, J. (2004) Urbanization effect on the observed change in mean monthly temperatures between 1951-1980 and 1971-2000 in Korea. Climatic Change 66(1), 127-136.

Correa, E., Martinez, C., Lesino, G., de Rosa, C., Canton, A. (2006) Impact of urban parks on the climatic pattern Mendoza's Metropolitan Area, in Argentina. PLEA 2006, The 23rd conference on passive and low energy architecture.

Deosthali, V. (2000) Impact of rapid urban growth on heat and moisture islands in Pune city, India. Atmospheric Environment 34, 2745-2754.

Eliasson, I., Upmanis, H. (2000) Nocturnal airflow from urban parksimplications for city ventilation. Theoretical and Applied Climatology 66(1/2), 95-107.

Fortin, M.J., Dale, M.R.T. (2005) Spatial Analysis - A Guide for Ecologist. Cambridge University Press, pp. 132-138.

Genton, M.G. (1995) Robustesse dans 1'estimation du variogramme: Bulletin de 1'Institut International de Statistique, Beijing, China, v. 1, pp. 400-401.

Gomez, F., Gaja, E., Reig, A. (1998) Vegetation and climatic changes in a city. Ecological Engineering 10(4), 355-360.

Gosling, S.N., Lowe, J.A., McGregor, G.R., Pelling, M., Malamud, B.D. (2009) Associations between elevated atmospheric temperature and human mortality: a critical review. Climatic Change 92, 299-341.

Howard, L. (1833) Climate of London Deduced from Meteorological Observations. (3rd Ed. Vol. 1), Harvey and Darton, London, pp. 348.

IPCC (2007) Climate change 2007: Synthesis report. Cambridge University Press.

Jauregui, E. (1997) Heat island development in Mexico City. Atmospheric Environment 31(22), 3821-3831.

Jauregui, E., Godinez, L., Cruz, F. (1992) Aspects of heatisland development in Guadalajara, Mexico. Atmospheric Environment 26B, 391-396.

Jonsson, P. (2004) Vegetation as an urban climate control in the subtropical city of Garborone, Botswana. International Journal of Climatology 24(10), 1307-1322.

Journel, A.G., Huijbregts, CH.J. (1981) Mining Geostatistics. Academic Press, New York.

Kim, Y.H., Baik, J.J. (2004) Daily maximum urban heat island intensity in large cities of Korea. Theoretical and Applied Climatology 79(3), 151-164.

Kim, Y.H., Baik, J.J. (2005) Spatial and temporal structure of the urban heat island in Seoul. Journal of Applied Meteorology 44(5), 591-605.

Klysik, K., Fortuniak, K (1999) Temporal and spatial characteristics of the urban heat island of Lodz, Poland. Atmospheric Environment 33, 3885-3895.

Korea Meteorological Administration (2001) Climatological Normals of Korea. (written in Korean)

Kwon, Y., Lee, H. (2001) Spatial distribution of temperature in and around urban parks. Journal of the Korean Geographical Society 36(2), 126-140. (written in Korean with English abstract)

Landis, J.R., Koch, G.G. (1977) The measurement of observer agreement for categorical data. Biometrics 33, 159-174.

Landsberg, H.E. (1981) The urban climate. Academic Press, New York, pp. 275.

Lee, S.H., Lee, K.S., Jin, W.C., Song, H.K. (2009) Effect of an urban park on air temperature differences in a central business district area. Landscape and Ecological Engineering 5(2), 183-191.

Lee, W.K., Biging, G.S., Son, Y., Byun, W.H., Lee, K.H., Son, Y.M., Seo, J.H. (2006) Geostatistical analysis of regional differences in stem taper form of Pinus densiflora in central Korea. Ecological Research 21(4), 513525.

Matheron, G. (1963) Principles of geostatistics. Economic Geology 58, 1246-1266.

MathSoft (1997) S-PLUS API object interface library, reference manual, beta version 0.3 Math- Soft, Inc.

Melesse, A.M. (2004) Spatiotemporal dynamics of land surface parameters in the Red river of the north basin. Physics and Chemistry of the Earth 29, 795-810.

Mobasheri, M.R., Mousavi, H. (2004) Remote sensing of suspended sediments in surface waters using MODIS images. Citeseer, 12-23.

Mowrer, H.T., Congalton, R.G. (2000) Quantifying spatial uncertainty in natural resources. Ann Arbor Press, Chelsea, pp. 244.

Narita, K., Mikami, T., Honjo, T., SuGWSara, H., Kimura, K., Kuwata, N. (2002) Differentiations about coolisland phenomena in urban park. Fourth symposium on the urban environment, American Meteorological Society, 20-24 May 2002, Norfolk, Virginia Abs 8.2, 8687.

Oke, T.R. (1981) Canyon geometry and the nocturnal urban heat island: Comparison of scale model and field observations. Journal of Climatology 1, 237-254.

Park, H.S. (1986) Features of the heat island in Seoul and its surrounding cities. Atmospheric Environment 20, 1859-1866.

Seoul Metropolitan Government (2001) Seoul Statistical Yearbook.

Smith, C.L., Lindley, S.J., Levermore, G.J., Lee, S.E. (2009) A GIS-based decision support tool for urban climate risk analysis and exploration of adaptation 
options, with respect to urban thermal environments. Proceedings of the seventh International Conference on Urban Climate 2009, Yokohama, Japan.

Song, I., Hong, S.K., Kim, H.O., Byun, B., Gin, Y. (2005) The pattern of landscape patches and invasion of naturalized plants in developed areas of urban Seoul. Landscape and Urban Planning 70(3-4), 205-219.

Suga, Y., Ogawa, H., Ohno, K., Yamada, K. (2003) Detection of surface temperature from LANDSAT-7/ETM+. Advances in Space Research 32(11), 2235-2240.

Svensson, M., Eliasson, I. (2002) Diurnal air temperatures in built-up areas in relation to urban planning. Landsc Urban Plan 61, 37-54.

Upmanis, H., Eliasson, I., Lindqvist, S. (1998) The influence of green areas on nocturnal temperatures in a high latitude city (Göteborg, Sweden). International Journal of Climatology 18(6), 681-700.

Webster, R., Oliver, M.A. (2001) Geostatistics for environmental scientists. Wiley, New York. pp. 271.
Webster, R., Oliver, M.A. (2007) Geostatistics for Environmental Scientists. (2nd Ed.) Wiley, New York, pp. 315.

Wong, N., Chen, Y. (2004) The thermal effects of city greens on surroundings under the tropical climate. PLEA2004 The 21th conference on passive and low energy architecture.

Yoon, Y. (2003) Air temperature variation by effect of green space condition. Journal of Korean Environmental and Restoration Technology 6(1), 28-33. (written in Korean)

Yoon, Y., Bae, B. (2002) A study on the relation between scale of green spaces and decreasing air temperature. Korean Journal of Environmental Biology 20(1), 1019. (written in Korean with English abstract)

(Received 15 November 2011, revised 25 May 2012, accepted 25 May 2012) 